\title{
Implementation of Microcontroller Based Smart Room
}

\author{
Thae Hsu Thoung \\ Lecturer \\ Technological University \\ Taunggyi, Myanmar
}

\author{
Aung Myo Htike \\ Lecturer \\ Technological University \\ Pyay, Myanmar
}

\author{
Dr. Zin Ma Ma Myo \\ Professor \\ Technological University \\ Thanlyin, Myanmar
}

\begin{abstract}
This paper describes the comfortable smart room control system. The system consists of room security, lighting control and appliances control. These individual sections can be controlled by simple $3 \times 4$ keypad. The proposed system is developed by PIC16F84A microcontroller. Assembly programming language is used to program the microcontroller and Proteus Design Suite 8.0 is used to simulate the design.
\end{abstract}

Keywords: PIC16F84A, microcontroller, 3×4 keypad, assembly programming language, Proteus Design Suite

\section{INTRODUCTION}

Fig.1 shows the block diagram of microcontroller based smart room. It is aimed to design a low-cost and ease of access system. The overall system can be divided into room security section, lighting control section and appliances control section. If only the correct password is entered, the door will be opened for room security. Lighting and home appliances can be switched on or off depending on the input key.

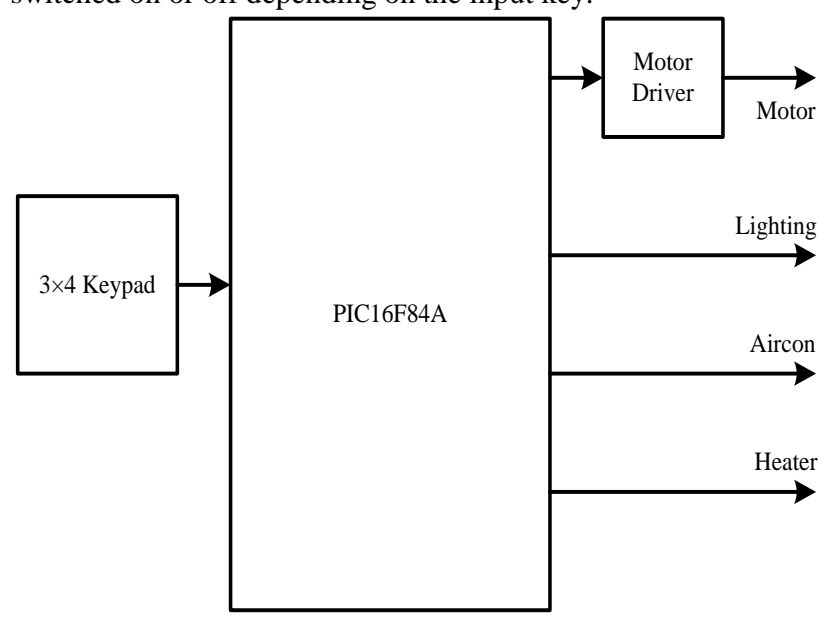

Figure. 1 Block diagram of control system for smart room

\section{SYSTEM DESCRIPTION}

\subsection{Hardware Requirements}

- $\quad 3 \times 4$ Keypad

- PIC16F84A Microcontroller

- Relay Unit

- Power Supply Unit

- Motor Driver

- Motor

- Home Appliances

\subsection{Software Requirements}

- MPLAB Integrated Development Environment (IDE)

- Proteus Design Suite 8.0

\section{SYSTEM IMPLEMENTATION}

The implementation programs can be categorized as follows:

- Study the relating theoretical background

- Consider the design requirements

- Design the components for the proposed system divided by three sections

- Consider the required assembly language program

- Assemble the program by using MPLAB IDE and correct the errors

- Simulate the overall system by using Proteus Design Suite 8.0

To reduce the number of I/O connections, keypads are usually arranged in a matrix format. A 12-key keypad is arranged in a $3 \times 4$ format requiring seven connections. [2] Fig. 2 shows the $3 \times 4$ keypad.

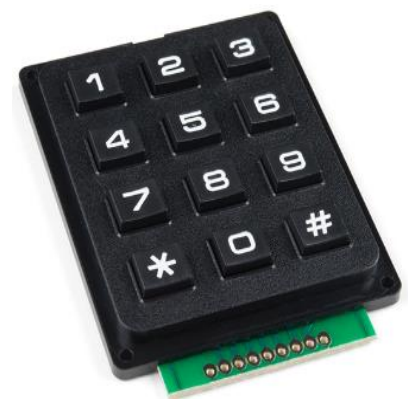

Figure. $23 \times 4$ keypad [8]

Table 1 shows the column and row condition for 12-key keypad. Each of the column is connected to RB0, RB1 and RB2 pin of microcontroller. RB3, RB4, RB5 and RB6 are connected to the four rows. 
Table 1 12-Key keypad

\begin{tabular}{|c|c|c|c|}
\hline & Column1 & Column2 & Column3 \\
\hline Row1, R1 & 1 & 2 & 3 \\
\hline Row2, R2 & 4 & 5 & 6 \\
\hline Row3, R3 & 7 & 8 & 9 \\
\hline Row4, R4 & $*$ & 0 & $\#$ \\
\hline
\end{tabular}

The PIC16F84A belongs to the mid-range family of the PIC microcontroller devices. The program memory contains $1 \mathrm{~K}$ words, which translates to 1024 instructions, since each 14-bit program memory word is the same width as each device instruction. The data memory (RAM) contains 68 bytes and data EEPROM is 64 bytes. [1]

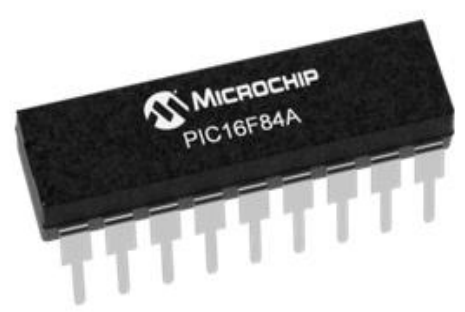

Figure. 3 PIC16F84A microcontroller [9]

There are also 13 I/O pins that are user-configured on a pin-topin basis. Fig. 4 shows the pin configuration of PIC16F84A microcontroller. [1]

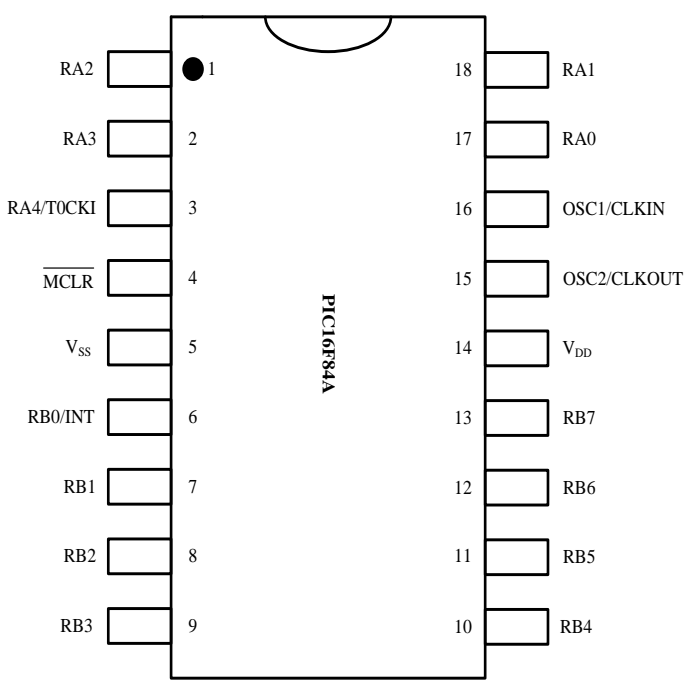

Figure. 4 Pin configuration of PIC16F84A microcontroller

The lighting unit is connected to RA0 via the relay circuit. The aircon unit is connected to RA1 whereas the heater is connected to RA2 pin. RA3 and RA4 pins are connected to motor driver. Fig. 5 shows the key specification in program.

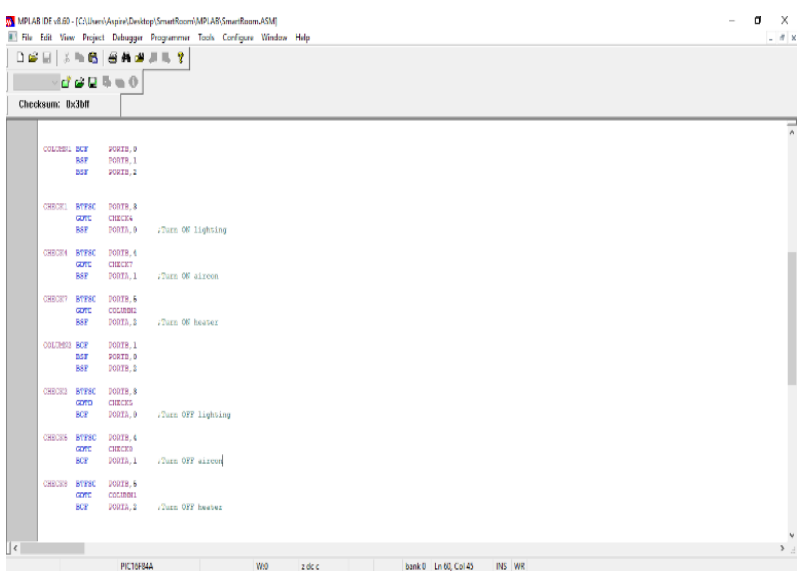

Figure. 5 Key specification for lighting and appliances

After writing the assembly language program, converting it to machine language program by using MPLAB IDE assembler.

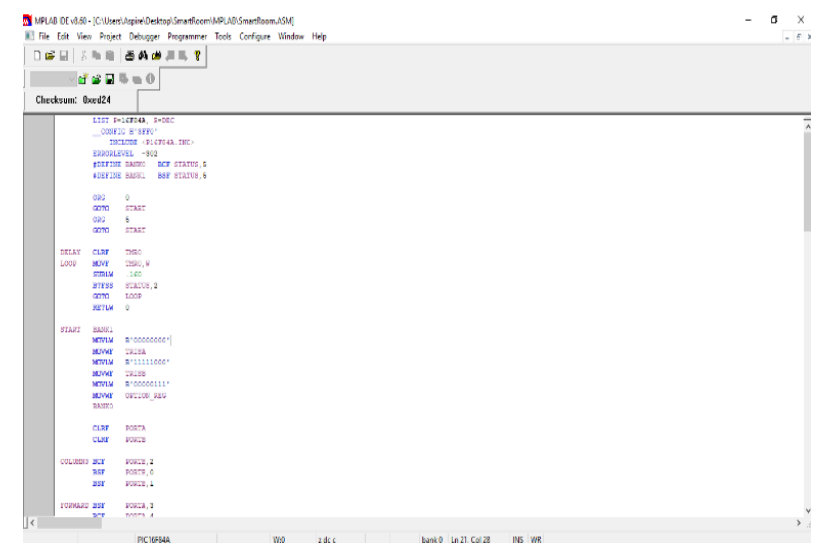

Figure. 6 Assembly language program

The configuration bits are specified according to the system as in Fig.7. Then the program is built to produce the machine code: HEX file. Fig. 8 shows the successful message of building processs.

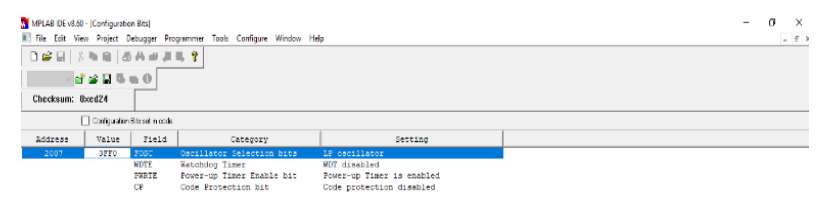

Figure. 7 Configuration bits for the proposed system 


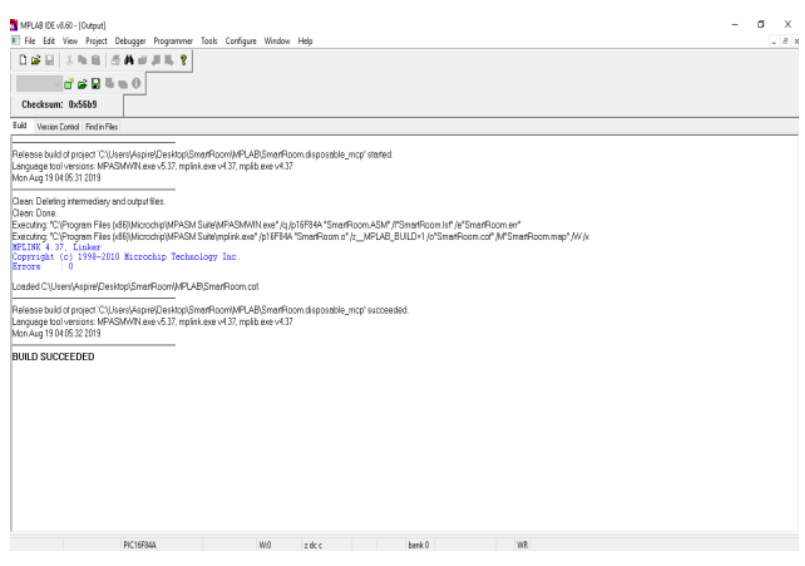

Figure 8 Building process

To simulate the design, sketch the design by using Proteus software. Then the machine code produced by assembler is inserted into microcontroller. Fig.9 shows the schematic diagram of proposed system.

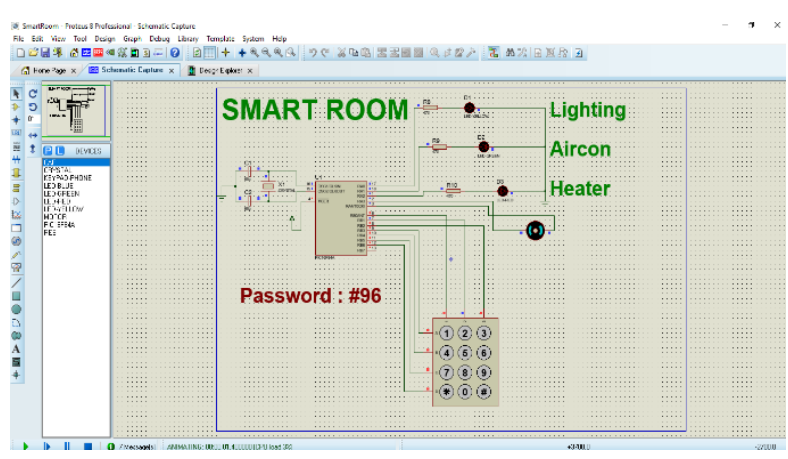

Figure.9 Schematic diagram of proposed system

\section{SYSTEM FLOWCHART}

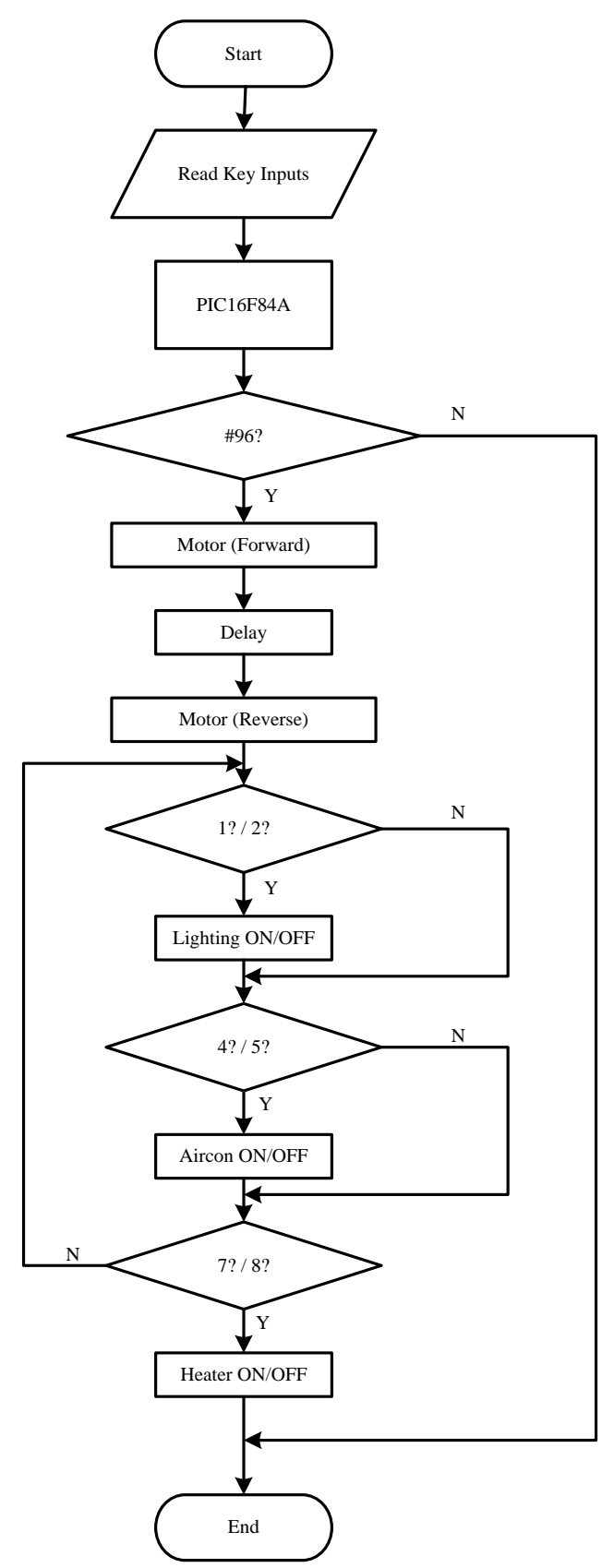

Figure. 10 Flowchart of smart room

The overall flowchart is shown in Fig.10. The security password is \#96. The door will be opened only the correct password is entered. Lighting and appliances will be $\mathrm{ON}$ or OFF according to the PORTB inputs.

\section{SIMULATION RESULTS}

If the correct password (\#96) is entered, the motor will be rotated in forward direction to open the door. After delay time the door will be automatically closed. 


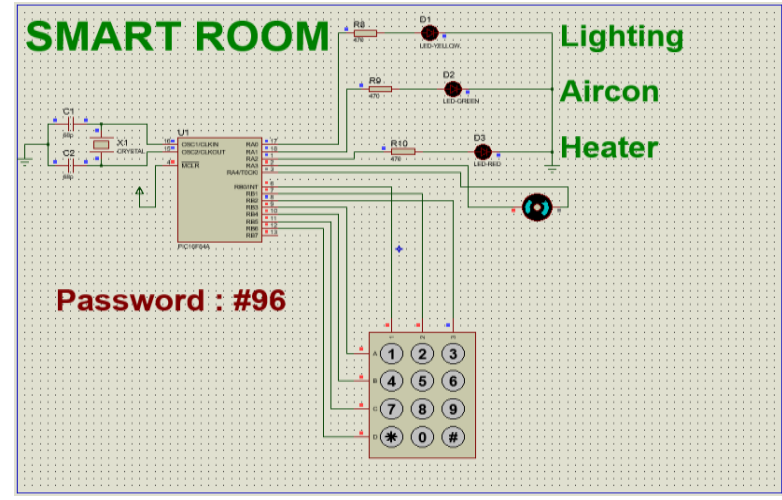

Figure. 11 Motor condition if correct password (\#96) is pressed

If key 1 is pressed, the lighting unit will be switched "ON" and it will be switched "OFF" when key 2 is pressed.

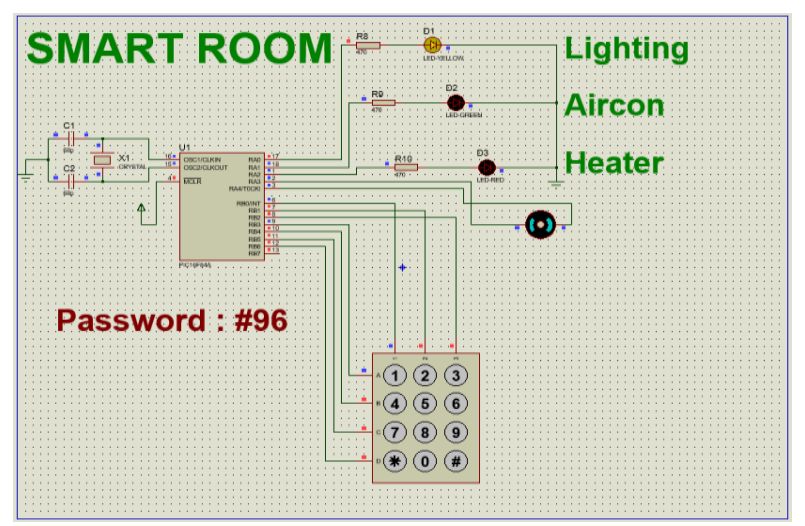

Figure. 12 Lighting condition

If key 4 is pressed, the aircon will be switched "ON" and it will be switched "OFF" when key 5 is pressed.

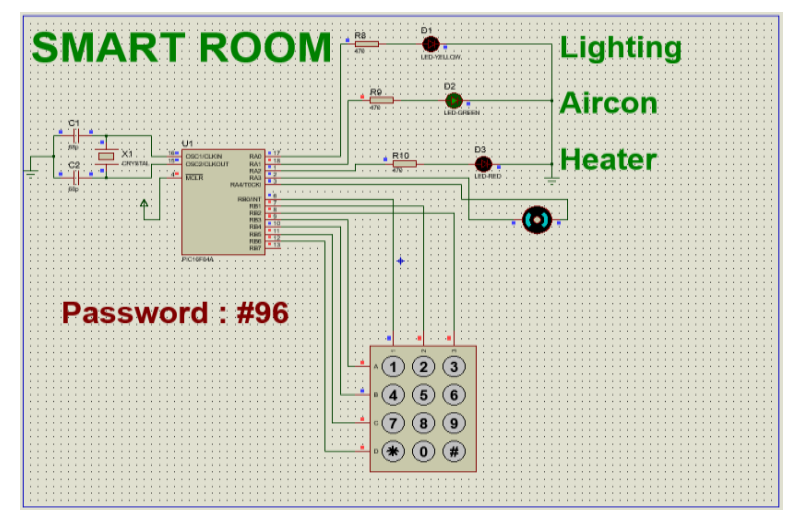

Figure. 13 Aircon condition

If key 7 is pressed, the heater will be switched "ON" and it will be switched "OFF" when key 8 is pressed.

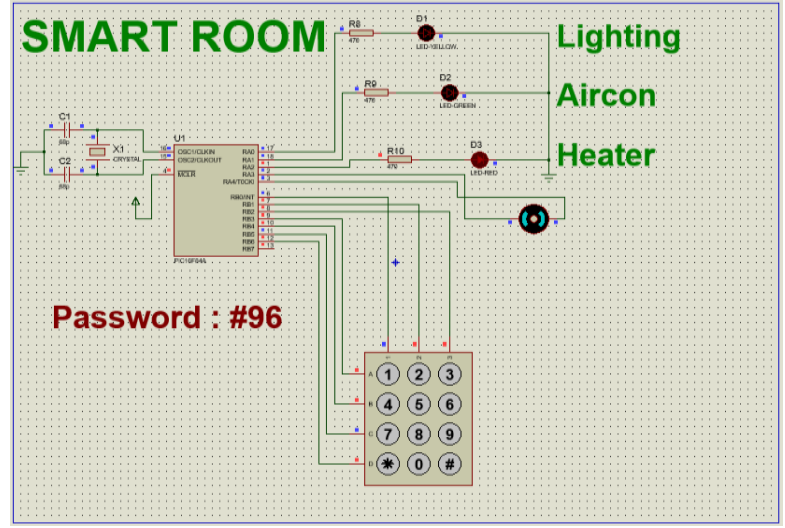

Figure. 14 Heater condition

\section{CONCLUSIONS}

The control system for smart room was designed and implemented. This system was composed of home security, lighting control and appliance control. It was used microcontroller (PIC16F84A) and keypad. MPLAB IDE was used to assemble the program and Proteus design suite was used to simulate the design.

\section{ACKNOWLEDGMENTS}

The author wishes to express her deep gratitude to Dr. Zin Ma Ma Myo, Professor and Head, Department of Electronic Engineering, Technological University (Thanlyin), for her permission and the support. The author is also indebted to all of her teachers in the Department of Electronic Engineering, who contributed their knowledge and support during the study and research periods. A special note of thank is also intended to Dr. Thet Mon Aye, Lecturer, Department of Electrical Power Engineering, West Yangon Technological University, who helped her with necessary assistance for her research.

\section{REFERENCES}

[1] Microchip Technology Inc. , (2001), "PIC 16F84A Datasheet"

[2] Di Jasio, Wilmshurst, Ibrahim, Morton, Bates, J.Smith, Hellebuyck, (2008), "PIC Microcontrollers"

[3] Assaf, M.H, "Sensor based home automation and security system", Instrumentation and Measurement Technology Conference (I2MTC), 2012 IEEE International

[4] Usha Devi, Y, (2012), "Wireless Home Automation System Using Zigbee, International Journal of Scientific \& Engineering Research ,Volume: 3, Issue: 8

[5] Lakhya, Inder, Emanual, Abhijit, Lalan, Debaraj, M. Sujitha, (2012), "Home Automation System Based on Arm and Zigbee", Undergraduate Academic Research Journal (UARJ), Volume: 1, Issue: 3,4

[6] Dhawan S. Thakur and Aditi Sharma, (2013), "Voice Recognition Wireless Home Automation System Based on Zigbee", IOSR - JECE, Volume: 6, Issue: 1

[7] https://en.wikipedia.org/wiki/Home_automation

[8] https://www.sparkfun.com/products/14662

[9] https://www.microchip.com/wwwproducts/en/PIC16F8A 